\title{
PRÁTICAS DE GESTÃO DE MARKETING MULTICANAL: ESTUDO NO VAREJO DE BENS DE CONSUMO
}

\author{
MANAGEMENT PRACTICES FOR MULTICHANNEL \\ MARKETING: STUDY ON RETAIL CONSUMER GOODS
}

\section{PRÁCTICAS DE GESTIÓN DE MARKETING MULTICANAL: ESTUDIO EN AL POR MENOR DE BIENES DE CONSUMO}

\author{
Aline Silva Autran de Morais \\ Mestre em Administração - UNISUL, \\ Florianópolis, Brasil \\ Professora de graduação - ESPM/Sul e UniRitter, \\ Porto Alegre, Brasil \\ alineautran@ideiamais.com.br \\ Aléssio Bessa Sarquis \\ Doutor em Administração - USP, São Paulo, \\ Brasil \\ Professor do Programa de Pós-Graduação em \\ Administração - UNISUL, Florianópolis, Brasil \\ alessio.sarquis@gmail.com

\section{Edson Roberto Scharf} \\ Doutor em Engenharia e Gestão do Conhecimento \\ - UFSC, Florianópolis, Brasil \\ Professor do Programa de Pós-Graduação em \\ Administração - FURB, Blumenau, Brasil \\ talentto@terra.com.br

\section{Jacir L. Casagrande} \\ Doutor em Engenharia de Produção - UFSC, \\ Florianópolis, Brasil \\ Professor do Programa de Pós-Graduação em \\ Administração - UNISUL, Florianópolis, Brasil \\ jacir.unisul@gmail.com
}

\author{
Contextus \\ ISSN 1678-2089 \\ ISSNe 2178-9258 \\ Organização: Comitê Científico Interinstitucional \\ Editor Científico: Diego de Queiroz Machado \\ Editor Executivo: Carlos Daniel Andrade \\ Avaliação: double blind review pelo SEER/OJS \\ Recebido em 23/01/2018 \\ Aceito em 13/07/2018 \\ $2^{a}$ versão aceita em 23/07/2018
}

\section{RESUMO}

As práticas de marketing multicanal se intensificaram no setor de varejo, causando beneficios e desafios para os lojistas. O estudo analisou as práticas de gestão de marketing multicanal de varejistas de bens de consumo da região Grande Florianópolis/SC, Brasil. Os dados foram coletados via questionário autoadministrado e analisados através de técnicas estatísticas. Resultados mostraram que o marketing multicanal é recente e utiliza vários canais on-line. As práticas mais utilizadas são: gestão da satisfação/reclamação de clientes, visual merchandising, portfólio de produtos/marcas, gestão do relacionamento com clientes e monitoramento da internet/redes sociais. Identificou-se diferença estatística significativa nas práticas de promoção/vendas, de alianças/parcerias, de integração na política de produtos e de preços em função do porte do varejista. Revelou-se a existência de quatro clusters de varejistas multicanal: "pioneiros", "experientes", "menos experientes" e "retardatários". O estudo contribuiu para ampliar o conhecimento sobre o tema na perspectiva dos varejistas, bem como para identificar diferenças estatísticas nas práticas de gestão de marketing multicanal em função do porte e de clusters na região estudada.

Palavras-chave: marketing; varejo; multicanal; integração; desempenho. 


\begin{abstract}
Multi-channel marketing practices have become more intense in the retail industry, causing benefits and challenges for retailers. This study analyzed the multichannel marketing management practices of retailers of consumer goods in Grande Florianópolis region, in the Brazilian state of Santa Catarina. Data were collected through a self-managed questionnaire and were analyzed with statistical techniques. Results have shown that multichannel marketing is recent and uses multiple on-line channels. The most commonly used practices are customer satisfaction management, visual merchandising, product/brand portfolio, customer relationship management, and internet/social network monitoring. Significant statistical differences were identified in the promotion/sales practices, alliances/partnerships, product and price policy integration depending on the size of the retailer. The existence of four clusters of multichannel retailers was found: "pioneering", "experienced", "less experienced" and "belated". The study contributed to increasing the knowledge about the subject from the perspective of the retailers as well as to identifying statistical differences in multichannel marketing management practices according to size and clusters in the region studied.
\end{abstract}

Keywords: marketing; retail; multi-channel; integration; performance.

\title{
RESUMEN
}

Las prácticas de marketing multicanal se intensificaron en el sector minorista, causando beneficios y desafíos para los comerciantes. El estudio analizó la gestión de marketing multicanal de los minoristas de bienes de consumo en la región Grande Florianópolis/SC, Brasil. Los datos fueron recolectados a través de cuestionario autoadministrado y analizados por técnicas estadísticas. Los resultados mostraron que el marketing multicanal es reciente y utiliza múltiples canales on-line. Las prácticas más utilizadas son: gestión de la satisfacción del cliente, comercialización visual, cartera de productos/marcas, gestión de las relaciones con los clientes y supervisión de redes sociales/Internet. Se identificaron diferencias estadísticas significativas en las prácticas de promoción/ventas, alianzas/asociaciones e integración de políticas de productos y precios, dependiendo del tamaño del minorista. Se reveló la existencia de cuatro grupos de minoristas multicanal: "pioneros", "experimentados", "menos experimentados" y "rezagados". El estudio contribuyó a aumentar el conocimiento sobre el tema desde la perspectiva de los minoristas y a identificar diferencias estadísticas en las prácticas de gestión de marketing multicanal según el tamaño y los clústeres en la región estudiada.

Palabras clave: marketing; venta al por menor; multicanal; integración; rendimiento.

\section{INTRODUÇÃO}

Em nível mundial, o setor de varejo tem enfrentado dificuldades e transformações. Lan (2010) apontou que a concorrência entre os varejistas se intensificou e que há necessidade de novas práticas de gestão de marketing. Acredita-se que o aumento da concorrência no setor seja resultado de pressões como o advento da internet (ZHANG et al., 2010; MATTAR, 2011), a entrada de competidores internacionais (PACAGNAN; RAMPAZO, 2008) e mudanças no perfil dos consumidores (BRYNJOLFSSON; HU; RAHMAN, 2013). Em decorrência desse ambiente competitivo, houve maior diversificação nos formatos de varejo e intensificou-se o uso da estratégia de marketing multicanal (MIOTTO; PARENTE, 2015).

O marketing multicanal envolve a utilização de diferentes canais (meios de contato) com os clientes, com o propósito de promoção, venda, distribuição e/ou comunicação (ZHANG et al., 2010). O varejo multicanal utiliza diferentes canais de vendas/distribuição, incluindo catálogo, loja física, telemarketing/call center, venda porta a porta, TV, home shopping, quiosque, máquina automática de vendas, website e mobile phone. $\mathrm{O}$ termo 
omnichannel tem sido utilizado para designar o uso integrado de diferentes canais de vendas/distribuição (AUBREY; JUDGE, 2012; VERHOEF; KANNAN; INMAN, 2015). O estudo de Cao e Li (2015) revelou que a integração de canais contribui para o crescimento de vendas. Sabe-se, também, que as práticas de gestão de marketing multicanal podem proporcionar benefícios como: ampliação da base de clientes e elevação no volume de vendas (KOZLENKOVA et al., 2015); aumento na lucratividade (VENKATESAN; KUMAR; RAVISHANKER, 2007); maior penetração de mercado (COUGHLAN et al., 2012; KOZLENKOVA et al., 2015); e melhoria nos serviços ao cliente (DIAS, 2014). O marketing multicanal pode, ainda, contribuir para a diferenciação e vantagem competitiva no varejo (BRYNJOLFSSON; HU; RAHMAN, 2013; HERHAUSEN et al., 2015).

As práticas de gestão de marketing multicanal trazem, no entanto, desafios para os varejistas, incluindo a necessidade de integrar dados, conhecer o comportamento dos clientes, ter novas métricas de avaliação do desempenho e alocar recursos para os diferentes canais (ZHANG et al., 2010). Também pode haver dificuldades decorrentes do acesso à internet de banda larga, na integração dos canais e na implementação de novas práticas de marketing multicanal (ZHANG et al., 2010). No Brasil, esses desafios podem ser maiores, devido à elevada fragmentação e informalidade do setor de varejo.

No Brasil, o setor de varejo tem papel econômico-social importante. Conforme o Departamento de Pesquisas e Estudos Econômicos (DEPEC, 2016), o comércio varejista representa $13 \%$ do PIB nacional e responde por $43 \%$ do comércio geral. A região Sul é a segunda maior em quantidade de estabelecimentos (22\%) e em receita bruta (19,7\%). Segundo a Federação do Comércio de Bens, Serviços e Turismo de Santa Catarina (FECOMÉRCIO-SC, 2016), o comércio de bens, serviços e turismo representa 62,4\% do PIB do Estado de Santa Catarina e gera 1,4 milhão de empregos. A região Grande Florianópolis possui mais de 27 mil empresas no comércio com atividade comercial forte e diversificada, bem como com lojas das principais redes varejistas do estado. Dessas redes, aquelas de bens de consumo cresceram 500\% nos últimos 10 anos (ROCHA, 2014). Além disso, informações da Fecomércio de Santa Catarina (FECOMERCIO, 2016) indicam, relativamente aos varejistas da região, baixo conhecimento sobre o marketing multicanal ou deficiências nessa prática, bem como falta de recursos para implementar novos canais. Sabe-se, também, que o setor de varejo na região é bastante fragmentado e se compõe principalmente de pequenas empresas, com atuação local. 
Consulta nas bases de dados Scielo, Ebsco, Scopus, Web of Science, Science Direct e Google Acadêmico, utilizando os descritores marketing multichannel e cross-channel, para o período de 2005 a 2015, identificou que os estudos sobre o tema tratam predominantemente de: canais de comunicação, mídia social, customer relationship management, branding, serviços, comportamento de compra, lealdade do consumidor, canibalização de canais, migração de canal e uso de canais específicos (como franchising ou e-commerce). Watson IV et al. (2015) apontaram que, na última década, as publicações sobre marketing multicanal cresceram mais de $150 \%$ e as bases teóricas dos estudos são, principalmente, conceitos econômicos e comportamentais. Verhoef, Kannan e Inman (2015) revelaram que, em nível internacional, os estudos sobre varejo multicanal foram focados em tópicos como impacto de diferentes canais no desempenho organizacional, comportamento de compra e mix de marketing no varejo. E Neslin e Shankar (2009) apontaram a necessidade de investigar melhor as práticas de gestão de marketing multicanal, incluindo canais de vendas/distribuição utilizados, práticas de integração de canais e o desempenho dos varejistas multicanal.

Diante desse contexto, decidiu-se realizar o presente estudo com a seguinte pergunta de pesquisa: quais são as práticas de gestão de marketing multicanal utilizadas pelos varejistas de bens de consumo? Com isso, o objetivo geral do estudo é analisar as práticas de gestão de marketing multicanal de varejistas de bens de consumo da região Grande Florianópolis/SC, Brasil. Especificamente, o estudo busca: identificar as práticas de gestão de marketing multicanal dos varejistas; identificar as práticas de integração de canais; verificar o desempenho competitivo dos varejistas multicanal; classificar os varejistas em clusters (grupos) com base nas práticas de gestão de marketing multicanal; e examinar possíveis diferenças tanto nas práticas de gestão de marketing multicanal, quanto no desempenho competitivo em função do porte dos varejistas. Este estudo está vinculado à teoria de marketing e de varejo multicanal, abordando apenas aspectos da prática de gestão de canais de vendas/distribuição dos varejistas, ou seja, não abrange os canais utilizados exclusivamente para comunicação e como mídias. O estudo pode contribuir para ampliar o conhecimento acadêmico sobre práticas gestoras de marketing multicanal de varejistas de bens de consumo e coletar evidências empíricas sobre o tema com perspectiva de análise diferenciada (opinião de gestores varejistas), já que a maioria dos estudos presentes na literatura foi realizada segundo a perspectiva do consumidor. 


\section{REVISÃO DA LITERATURA}

\subsection{Marketing multicanal}

No processo de vendas/distribuição, um canal de marketing compreende um conjunto de organizações interdependentes envolvidas na disponibilização de bens/serviços para o usuário final (KOTLER; KELLER, 2012). Entende-se, também, por canais de marketing os meios (físicos e eletrônicos) utilizados pela organização com propósito de vendas e atendimento aos clientes. Alguns autores classificam os canais de marketing em canais de loja (físico) e canais sem loja (DHOLAKIA; ZHAO; DHOLAKIA, 2005; KIM; LEE, 2008; ZHANG et al., 2010; PARENTE; BARKI, 2014). Dholakia, Zhao e Dholakia (2005), por exemplo, definem canal de loja um ponto físico, com horário de compras limitado e que permite aos clientes contato com as mercadorias e interação presencial com atendentes. Nesse caso, o consumidor pode experimentar os produtos, ter atendimento presencial e vivenciar experiência social de compra, utilizando os cinco sentidos humanos (KIM; LEE, 2008; ZHANG et al., 2010).

Já o canal sem loja compreende o uso de canais não baseados em loja física. Conforme Kaufman-Scarborough e Lindquist (2002), os canais sem loja são aqueles que possibilitam ao cliente navegar, pesquisar e comprar pela internet, televisão, catálogo impresso e/ou telefone, por exemplo. Parente e Barki (2014) apresentam como exemplos de varejo sem loja: marketing direto, venda pessoal direta, venda por máquina automática e varejo virtual. Tais canais proporcionam a possibilidade de compra a qualquer momento, de forma fisicamente segura, rápida e sem custo de deslocamento. Esses canais permitem acesso a novos mercados/clientes, sem o custo operacional das lojas físicas (ZHANG et al., 2010).

Em decorrência do avanço da tecnologia/internet e do acirramento no ambiente competitivo, uma das estratégias utilizadas no varejo é o marketing multicanal (BRUCE et al., 2009). Nos últimos anos, as práticas de marketing multicanal se intensificaram, incluindo o uso de loja física, loja virtual, catálogo impresso, força de vendas externa, representante de vendas, call center e outros canais eletrônicos (NESLIN; SHANKAR, 2009). Parente e Barki (2014) destacaram que o varejo multicanal é mais do que ter loja física e loja on-line, e envolve a prática de oferecer aos clientes diferentes canais de vendas/atendimento, tanto offline como on-line. Esses autores propuseram um modelo de classificação de canais de marketing em quatro categorias: canais mobile (smartphones, tablets), canais de multimídia 
não mobile (televisão, rádio, computador), canais off-lines (catálogos, lojas físicas, venda porta a porta) e canais alternativos (gôndolas virtuais no metrô ou pôsteres com $q$ code reader).

Estudos anteriores revelaram que os clientes multicanais são mais rentáveis e gastam mais do que os de canal único (VENKATESAN; KUMAR; RAVISHANKER, 2007; KUSHWAHA; SHANKAR, 2013; DIAS, 2014). Por exemplo, a pesquisa do International Data Corporation, denominada IDC Retail Insights, identificou que o consumidor multicanal gasta cerca de $15 \%$ a $30 \%$ mais do que o consumidor de canal único (DIAS, 2014). Neslin e Shankar (2009) afirmaram que a estratégia de multicanal está associada ao volume de vendas e à lealdade dos clientes, e que os varejistas multicanais são mais lucrativos. Acredita-se, também, que o varejo multicanal pode aumentar a satisfação e a lealdade dos clientes, bem como elevar a participação do varejista no volume de compra dos clientes (ZHANG et al., 2010; VANHEEMS; KELLY; STEVENSON, 2013). Possibilita, ainda, oferecer bens/serviços diferenciados, competir em mercados amplos e melhorar o desempenho competitivo do varejista (MÜLLER-LANKENAU; WEHMEYER; KLEIN，2006; WALLACE; JOHNSON; UMESH, 2009).

Alguns estudos indicam, ainda, que a estratégia de marketing multicanal possibilita oferecer maior portfólio de produtos (ANSARI; MELA; NESLIN, 2008; VANHEEMS; KELLY, 2009; KUSHWAHA; SHANKAR, 2013), ampliar o relacionamento com clientes (ANSARI; MELA; NESLIN, 2008; VANHEEMS; KELLY, 2009), fomentar a migração dos clientes para canais mais convenientes (ANSARI; MELA; NESLIN, 2008) e melhorar a lucratividade da empresa (VANHEEMS; KELLY, 2009). Zhang et al. (2010) identificaram que os dados/informações coletados nas transações pela internet contribuem para melhorar o desempenho de marketing do varejista. Além disso, o estudo de Neslin e Shankar (2009) revelou que a venda por multicanal possibilita: economia de escala (mais canais geram mais oportunidades e menores custos de comercialização), economia de escopo (custos e recursos podem ser compartilhados entre os canais) e otimização de recursos (programas coordenados, comunicação integrada e proposição de valor unificada).

A pesquisa de Vanheems, Kelly e Stevenson (2013) revelou que o website tende a reforçar a credibilidade e experiência da empresa e dos vendedores, e que a integração de canais beneficia o relacionamento entre vendedor e clientes. Já o estudo de Cao (2014) revelou que a loja on-line ajuda no desenvolvimento de novos bens/serviços, pois facilita o 
lançamento, a coleta de dados sobre clientes e a avaliação de desempenho do produto. De fato, a loja física pode servir como showroom de produtos, um ponto de exposição e de serviços aos clientes. O estudo de Jones e Livingstone (2015) apontou que a localização da loja física, assim como o tamanho da loja e do portfólio de produtos contribuem para o desempenho das vendas nos canais on-line. No caso da loja inglesa Debenhams, a loja física contribuiu para melhorar o showroom dos produtos e para elevar em $30 \%$ a penetração da empresa no mercado on-line.

A gestão de marketing multicanal tende, no entanto, a ser mais complexa e desafiadora. Pode requerer, por exemplo, maior estrutura/recursos de marketing, mais investimentos em capacidades (como tecnologia e pessoal especializado), aprimoramento dos serviços de logística (ROSENBLOOM, 2007; VALOS, 2008) e integração entre os diferentes canais, inclusive em nível de políticas de produtos e preços (BERRY et al., 2010). Neslin e Shankar (2009) alertaram que alguns varejistas estão adicionando novos canais de vendas simplesmente para seguir a concorrência, sem a adequada avaliação de dificuldades operacionais e do impacto dessa estratégia no desempenho da empresa. E o estudo exploratório de Rapp et al. (2015) encontrou eventuais efeitos negativos da prática de showrooming sobre o desempenho da equipe de vendas, mesmo que estes efeitos possam ser atenuados por práticas e comportamento adequado da equipe de vendas das lojas físicas.

Operar com vários canais de vendas requer modificação frequente nas estratégias de marketing, incluindo ampliação da oferta de serviços e investimentos na gestão de estoques e entrega de produtos (KUMAR; SUNDER; SHARMA, 2015). Há, também, o risco de que o aumento na receita de vendas não represente melhoria na lucratividade do varejista (COUGHLAN et al., 2012) e que as práticas de gestão de marketing multicanal possam reduzir as vendas em outros canais da empresa (HERHAUSEN et al., 2015). A oferta excessiva de multicanais pode, também, gerar confusão no consumidor na compra de produtos/marcas, principalmente quando há falta de integração nas informações da comunicação de marketing dos diferentes canais (BROLIO; ESPARTEL, 2016). Assim, é preciso avaliar previamente o impacto da estratégia de marketing multicanal no comportamento dos clientes e no desempenho do varejista. Requer, ainda, investimentos nos processos de entrega de bens, serviços aos clientes e gestão de informações; e a gestão de conflitos (internos e externos) que possam ser causados pelos canais emergentes (VALOS et al., 2010). 


\subsection{Práticas de gestão de marketing multicanal}

Coughlan et al. (2012) apontaram algumas práticas de gestão na estruturação de canais de marketing: entender a demanda e as características dos clientes; definir os tipos e a quantidade de canais; distribuir a carga de trabalho pelos canais (tarefas, responsabilidades e custos); determinar o grau de integração dos canais; avaliar as fontes de poder e dependência dos canais; gerir conflitos de canais. Neslin e Shankar (2009) acrescentam: analisar o comportamento dos clientes-alvo; desenvolver estratégias de produtos, preços, logística; e avaliar o desempenho dos canais. A Figura 1 apresenta esse modelo. Bernstein, Song e Zheng (2008) apontaram: realizar alianças estratégicas com outros varejistas para elevar a produtividade e reduzir os investimentos na abertura de novos canais e os custos de vendas. Para Quader e Quader (2008), alianças estratégias com empresas dotcom facilitam a transição para o multicanal e reduz problemas com a falta de experiência on-line e com a manutenção do website.

Sobre a Figura 1, a empresa busca, na fase de análise de clientes, entendê-los, segmentar a base de clientes, selecionar o segmento-alvo e avaliar as estratégias de marketing. Recomenda-se que essa segmentação de clientes seja feita com base nas preferências, capacidade de resposta e potencial de crescimento dos clientes.

Figura 1 - Modelo conceitual da gestão de clientes multicanal

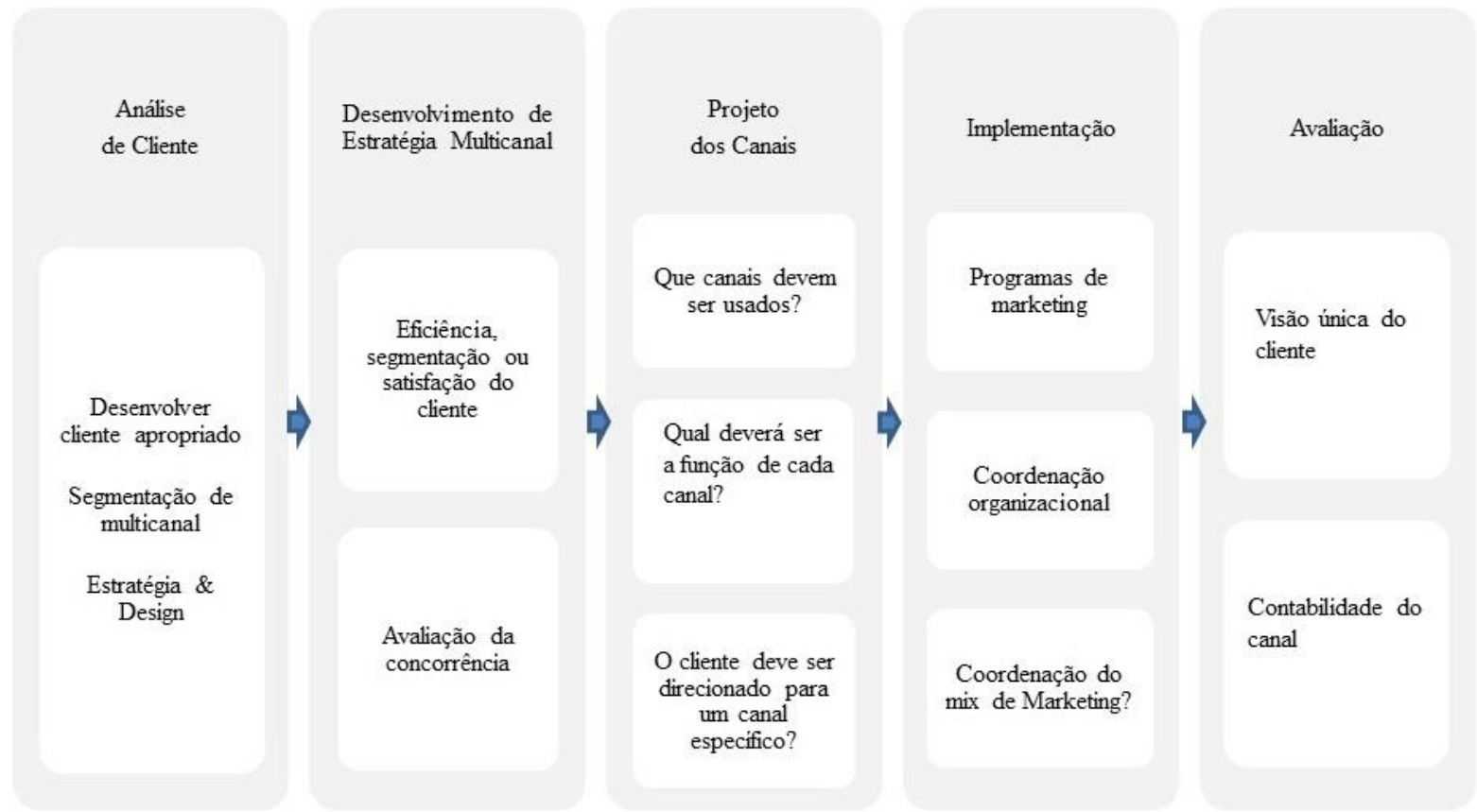

Fonte: Neslin e Shankar (2009). 
A fase de desenvolvimento da estratégia multicanal compreende a definição da estratégia de multicanal, considerando os critérios de eficiência, segmentação e satisfação dos clientes. Nessa fase, faz-se também a avaliação da concorrência, incluindo análise do desempenho e das estratégias utilizadas. A fase de projeto de canais abrange a definição dos canais a serem usados, a função/papel de cada canal e a possibilidade de redirecionamento de clientes para canais específicos. Na implementação, é criado o programa de marketing, e se definem a estrutura organizacional necessária e o responsável por coordenar o mix de marketing. A fase final, a avaliação, envolve a análise do desempenho dos canais, na visão do cliente e a contabilidade do canal.

Com relação às práticas na operacionalização de multicanais, Jin, Park e Kim (2010) recomendam investimentos na reputação da marca, na satisfação de clientes, em merchandising no ponto de venda, na promoção de vendas e na comunicação de marketing. $\mathrm{O}$ varejista multicanal pode, ainda, necessitar investir na qualificação de funcionários, na variedade de produtos/marcas, nos serviços de logística e no gerenciamento de reclamações/devolução de produtos. Outros exemplos de práticas de gestão de marketing multicanal são o monitoramento da internet/redes sociais, a realização de visitas/contatos periódicos com clientes e o alinhamento de recompensas dos membros de canais, incluindo contratos de manutenção de preços, investimento em publicidade cooperada, gerenciamento de conflitos e ações de viabilização da rentabilidade desejada (WALLACE; JOHNSON; UMESH, 2009).

Um dos componentes essenciais na gestão de marketing multicanal é a integração dos canais. Conforme Müller-Lankenau, Wehmeyer e Klein (2006), tal integração compreende utilizar diferentes canais de vendas/distribuição, de maneira complementar, integrada e sinérgica no atendimento aos clientes. Zhang et al. (2010) a definiram como oferecer aos clientes serviços de vendas/atendimento alinhados, inclusive com opção de compra de produtos em um canal e possibilidade de retirada ou devolução em outro canal. Entende-se que há integração de canais quando os clientes podem, por exemplo, consultar produtos no website da loja, efetuar compra na loja virtual e retirar na loja física (GRIFFITHS; HOWARD, 2008; JIN; PARK; KIM, 2010; ZHANG et al., 2010); quando existem ações de direcionando dos clientes entre os canais (NESLIN; SHANKAR, 2009); quando o varejista investe na integração dos diferentes canais por meio de políticas de produtos e comunicação de marketing (GRIFFITHS; HOWARD, 2008); quando o varejista dispõe de inventários e ações de merchandising integrados (PARK; KIM, 2010). 
Vários pesquisadores advogam a importância da integração de canais no varejo (BRUCE et al., 2009; XIA; ZHANG, 2010; VANHEEMS; KELLY; STEVENSON, 2013; CAO; LI, 2015; MELIS et al., 2015). Melis et al. (2015), por exemplo, afirmaram que para conquistar a lealdade de clientes o varejista precisa ofertar a mesma variedade de produtos e política de atendimento integrada nos canais off-line e on-line. Vanheems, Kelly e Stevenson (2013) afirmaram que requer integração no âmbito da experiência de compra do cliente, ou seja, mesma qualidade percebida dos serviços nos ambientes de compra. Bruce et al. (2009), Cao e Li (2015) e Xia e Zhang (2010) afirmaram que os consumidores multicanais preferem canais de vendas integrados e que a integração de canais favorece o aumento nas receitas de vendas. No passado, Bruce et al. (2009) defenderam que poucas empresas conseguem dominar plenamente a integração de canais e que a maioria delas não passa do estágio inicial da operação multicanal.

Há diversas práticas de integração de canais aplicáveis no varejo. Cao (2014) cita, por exemplo, a integração de sistemas de informação, a centralização de compras, a otimização da logística e o alinhamento das fontes de financiamento. Andreini e Pedeliento (2014) propuseram um modelo de integração contendo três componentes: canal independente (canais de vendas separados e, eventualmente, operados por meio de organizações independentes); canais integrados por banco de dados (quando o varejista utiliza tecnologias digitais de integração e canais que compartilham o mesmo banco de dados); canais totalmente integrados (quando os canais estão plenamente unificados e alinhados). A integração de canais tende a requerer investimentos em Tecnologia da Informação (TI) e nos processos, estrutura e recursos humanos. O estudo de Oh, Teo e Sambamurthy (2012) apontou que a TI desempenha papel viabilizador da integração de canais e permite melhorar a alocação de recursos, a gestão de processos e a avaliação do desempenho. O estudo de Yan, Wang e Zhou (2010) indicou que a integração de canais facilita a coordenação de canais e reduz os conflitos internos, especialmente no caso de varejistas de loja física com e-commerce.

Por fim, a seleção de estratégias de multicanal tende a requerer prévia análise dos segmentos de mercado e do comportamento de migração dos clientes (KUSHWAHA; SHANKAR, 2013). Requer, também, identificar os clientes mais rentáveis e analisar se é melhor fomentar a lealdade a determinado canal ou a migração entre canais (VANHEEMS; KELLY, 2009). Pentina, Pelton e Hasty (2009) sugeriram que os varejistas analisem dois fatores principais: os recursos organizacionais (como tamanho da empresa, idade e experiência de canal) que podem contribuir para alavancar a entrada em novos canais; e o 
estabelecimento dos objetivos de marketing para cada canal, seja em volume de vendas, participação de mercado, margem bruta e/ou custos operacionais. Ademais, o estudo de Johansson e Kask (2017) revelou que os gestores escolhem os canais de marketing em função do potencial de lucratividade, e que não existe uma solução única para todos os varejistas. Apontou também que é possível obter vantagem competitiva quando a configuração de multicanal está alinhada com a estratégia de negócio do varejista.

\section{ASPECTOS METODOLÓGICOS}

O presente estudo compreende pesquisa empírica, de abordagem quantitativa, descritiva e na forma de levantamento de campo (MALHOTRA, 2012). O levantamento de campo envolveu uma pesquisa descritiva, com instrumento de coleta estruturado e a coleta de dados quantitativos sobre as práticas de gestão de marketing multicanal e sobre o desempenho competitivo dos varejistas. Conforme Saunders, Lewis e Thomhill (2009), a pesquisa descritiva busca apresentar características de determinada população e emprega técnicas padronizadas de coleta de dados.

A população do estudo foi o conjunto de varejistas com atividade formal, que comercializam bens de consumo, localizados na região Grande Florianópolis, Santa Catarina (Brasil) e que operam em vendas por multicanal (com pelo menos dois canais, sejam físicos ou eletrônicos). O estudo abrangeu apenas organizações cuja principal fonte de receita provém da atividade de varejo (ZHANG et al., 2010) e que atuam no ramo de bens de consumo (produto físico), sejam duráveis, semiduráveis e não duráveis (KOTLER; KELLER, 2012; ZHANG et al., 2010), tais como lojas de ferragens, supermercados, veículos, eletrodomésticos, móveis, vestuários, acessórios, drogarias e alimentos. Foram pesquisados os varejistas localizados nos municípios Águas Mornas, Antônio Carlos, Biguaçu, Florianópolis, Governador Celso Ramos, Palhoça, Santo Amaro da Imperatriz, São José e São Pedro de Alcântara. Essa população foi estimada em 2.322 lojistas, com base nas listagens de associados da Federação das Câmaras de Dirigentes Lojistas de Santa Catarina (FCDL/SC) e da Federação do Comércio de Bens, Serviços e Turismo de Santa Catarina (Fecomércio-SC) em abril/2016. A amostra final contém 90 varejistas (questionários considerados válidos) que aceitaram voluntariamente participar do estudo. Assim, trata-se de amostragem por 
conveniência (não probabilística). Os respondentes foram proprietários, gerentes de loja ou gestores de marketing.

O método de coleta foi questionário autoadministrado, disponibilizado na plataforma SurveyMonkey, acompanhado de carta-convite, com apoio da FCDL-SC, Fecomércio-SC, Associação Empresarial de Palhoça (ACIP) e do SEBRAE/Florianópolis. Um e-mail convite foi enviado por essas entidades aos varejistas associados. Para ampliar a quantidade de participantes, alguns questionários foram aplicados pessoalmente e em cursos/eventos do SEBRAE/Florianópolis. A coleta de dados ocorreu no período de novembro/2016 a março/2017. O questionário foi elaborado com perguntas em escala intervalar de frequência de uso das práticas de gestão de marketing multicanal (5 pontos, sendo 1=“pratica nunca" e 5="pratica sempre"), contendo 16 variáveis indicadoras definidas a partir dos estudos de Neslin e Shankar (2009) e Zhang et al. (2010); e das práticas de integração de canais contendo 15 variáveis indicadoras baseadas nos trabalhos de Cao e Li (2015) e Kersmark e Staflund (2015). Já as perguntas sobre avaliação do desempenho competitivo dos varejistas foram elaboradas em escala ordinal de desempenho em relação ao principal concorrente (5 pontos, sendo 1="pior que a concorrência", 3="igual a concorrência" e 5="melhor que a concorrência"), contendo 6 variáveis indicadoras extraídas dos critérios propostos por Day e Wensley (1988) e Weltevreden e Boschma (2008). Foram incluídas também questões de qualificação e perfil dos respondentes. O questionário passou pelos processos de validação de face e pré-teste, buscando assegurar a confiabilidade e validade. Na validação de face, participaram os gestores da FCDL/SC e Fecomércio-SC, e o sócio-diretor de uma empresa de consultoria em varejo. Enquanto o pré-teste foi realizado com 10 varejistas (farmácias, lojas de vestuários e lojas de acessórios femininos) e possibilitou melhorias como reordenação de perguntas e troca de palavras/expressões que facilitariam o entendimento. O Apêndice A apresenta detalhes sobre as dimensões e variáveis indicadoras mensuradas.

Quanto ao método de análise, o preenchimento dos questionários foi previamente verificado, com a eliminação dos casos considerados não válidos. Foi feita, também, a verificação da validade e confiabilidade do questionário pelas técnicas Alpha de Cronbach (CRONBACH, 1951), variância média extraída (VME) e confiabilidade composta (CC). Os resultados da consistência interna indicaram que o instrumento tem confiabilidade alta ( $\alpha=0,841$ ), sendo $\alpha=0,740$ na dimensão práticas de gestão de marketing multicanal, $\alpha=0,904$ na dimensão práticas de integração de canais, e $\alpha=0,68$ na dimensão desempenho competitivo dos varejistas. Os cálculos de variância média extraída (VME) e confiabilidade composta 
(CC) resultaram em valores aceitáveis (gestão de marketing multicanal VME=0,61 e $\mathrm{CC}=0,64$; integração de canais $\mathrm{VME}=0,72$ e $\mathrm{CC}=0,76$; desempenho competitivo $\mathrm{VME}=0,79$ e $\mathrm{CC}=0,73$ ). Por fim, foi analisado o pressuposto de gaussianidade das variáveis. Os resultados de assimetria e curtose apontaram que 57,1\% das variáveis mensuradas atendem ao parâmetro desejado (entre 1 e -1); assim a maioria dos dados coletados se aproxima de uma distribuição considerada normal e permitem aplicar os testes estatísticos desejados.

Os dados coletados foram analisados com auxílio das técnicas frequência relativa, média, mediana e desvio-padrão. Como recomenda Malhotra (2012), os testes t de Student (para as variáveis intervalares) e ANOVA one-way (nas variáveis ordinais) foram utilizados para examinar possíveis diferenças estatísticas nas práticas de gestão de marketing multicanal e no desempenho competitivo em função do porte/tamanho dos varejistas. Com base nos critérios de classificação do Sebrae (2017), considerou-se: micro/pequena <50 funcionários; médio/grande $\geq 50$ funcionários. Depois, a técnica de estatística multivariada Cluster Analysis foi utilizada para classificar os varejistas em clusters, com base nas práticas de gestão de marketing multicanal. Os dados foram analisados com auxílio dos softwares Microsoft Excel e IBM SPSS.

\section{APRESENTAÇÃO E ANÁLISE DOS RESULTADOS}

\subsection{Perfil da amostra}

A amostra do estudo tem perfil diversificado. Há varejistas de diferentes ramos de atividade, portes, canais de vendas, tempo de uso do multicanal e percentual de investimento em marketing. Dos 90 varejistas pesquisados, há varejistas dos ramos de artigos de vestuários, calçados e acessórios (36\% da amostra); casa, móveis e decorações (20\%); materiais de construção (10\%); artigos para esporte e lazer (7\%); supermercados (7\%); equipamentos e suprimentos de informática (7\%); cosméticos, perfumaria e higiene pessoal (7\%); eletrodomésticos e equipamentos de áudio/vídeo (7\%); equipamentos de telefonia e comunicação (7\%). Sobre os canais de vendas, os varejistas utilizam redes sociais (82\%), lojas de rua (76\%), loja virtual (50\%), e-mail (36\%), telemarketing (24\%), representantes de vendas (18\%), loja em shopping (16\%), outros varejistas on-line, incluindo Mercado Livre e 
OLX (13\%), catálogos (11\%) e blogs (10\%). Assim, os canais sem loja (principalmente redes sociais, loja virtual e e-mail) são os mais utilizados.

Quando ao porte da empresa, cerca de $60 \%$ dos varejistas pesquisados são microempresa (até 9 funcionários), 19\% pequena empresa (10 a 49 funcionários), 14\% grande empresa (+100 funcionários) e 7\% empresa de médio porte (50 a 99 funcionários). Os varejistas de microporte têm, em média, 4 funcionários; pequeno porte tem 19 funcionários; médio porte tem 67 funcionários. Já os varejistas de grande porte têm, em média, 1.276 funcionários. Sobre o tempo de uso do multicanal, cerca de 53\% da amostra utiliza multicanal há até 3 anos; $15 \%$ há 10 ou mais anos. Os varejistas de micro/pequeno porte praticam multicanal há menos tempo. Em 2015, a média de investimento em marketing dos varejistas pesquisados é $3,6 \%$ do faturamento, com mediana $2 \%$ e moda $1 \%$. Cerca de $84 \%$ deles investiram até $5 \%$ do faturamento e $16 \%$ investiram entre 5,1 a $10 \%$ do faturamento. Os varejistas de pequeno/médio porte investiram percentualmente mais do que os varejistas de grande porte.

\subsection{Resultados de práticas de gestão de marketing multicanal}

O Gráfico 1 apresenta os resultados de práticas de gestão de marketing multicanal (somatório do percentual das escalas 4 e 5), por porte/tamanho e total, incluindo média e desvio-padrão. Os resultados indicam que a grande maioria dos varejistas pesquisados investe em: gestão da satisfação/reclamação de clientes (84\%), visual merchandising (83\%), portfólio de produtos/marcas competitivos (76\%), gestão do relacionamento/lealdade com clientes $(75 \%)$ e monitoramento da internet/redes sociais $(70 \%)$.

As práticas de gestão de marketing multicanal menos utilizadas são: ações de comunicação de marketing (49\%), incentivo ao uso de diferentes canais (48\%), sistemas de dados/informações sobre clientes (44\%) e aliança/parcerias com outras empresas/varejistas do mercado (41\%). Assim, diferente do que foi apontado no estudo de Watson IV et al. (2015), que revelou crescimento da network em canais, menos da metade dos varejistas pesquisados fazem uso de alianças/parcerias com outras empresas/varejistas (41\%) e apenas $44 \%$ deles faz uso de sistemas de dados/informação sobre clientes. Acredita-se que a prática de aliança/parceria com outras empresas/varejistas poderia ser mais frequente nos varejistas 
pesquisados (principalmente aqueles de micro/pequeno porte), pois pode contribuir para o diferencial competitivo (por ser, ainda, pouco utilizada na região) e para melhorar o desempenho dos canais disponibilizados, como sugerem Jin, Park e Kim (2010).

Gráfico 1 - Práticas de gestão de marketing multicanal (escalas 4 e 5), por porte e total

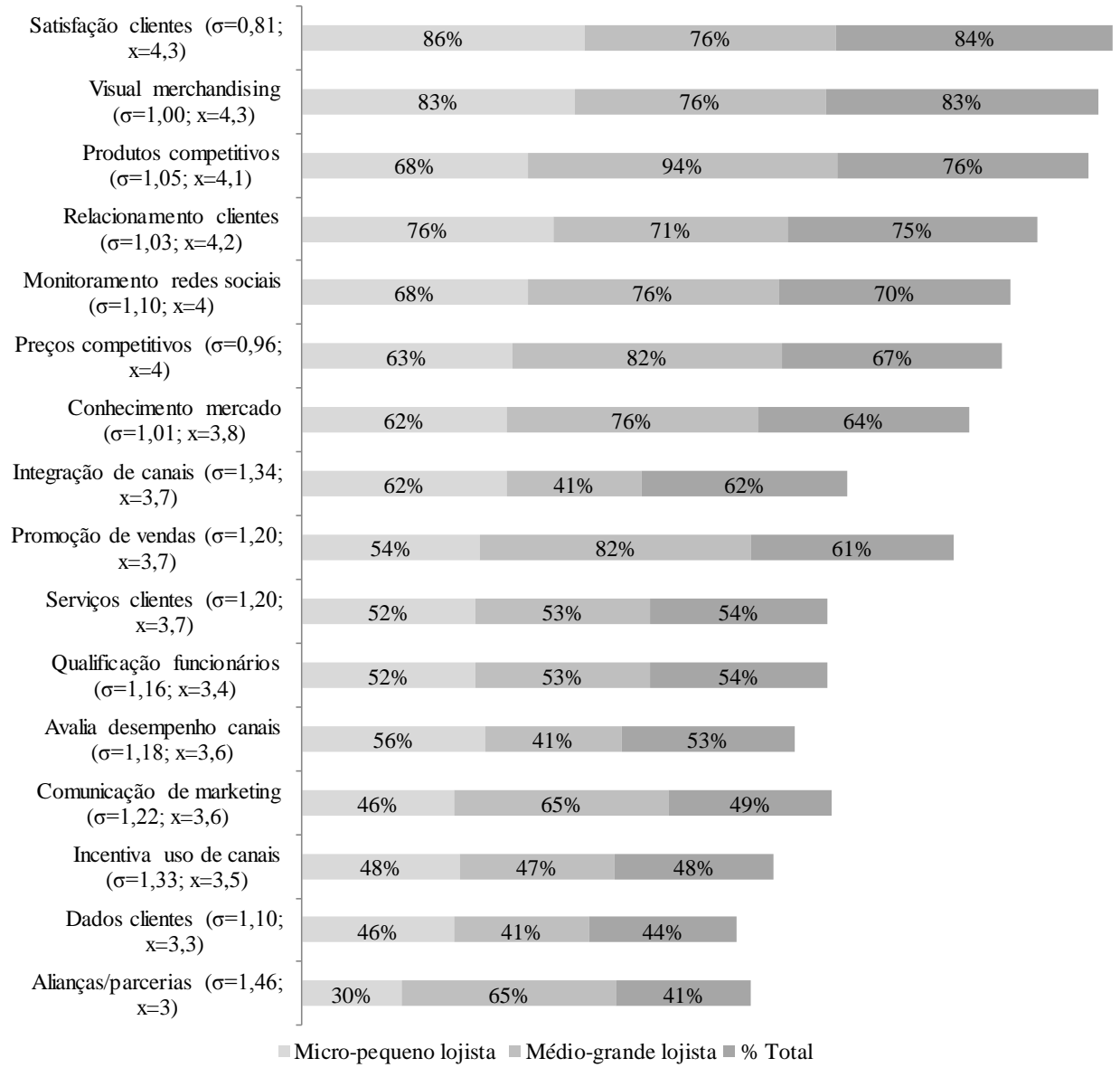

Fonte: elaboração própria.

Com relação ao porte/tamanho, os resultados mostram que a maioria dos varejistas de micro/pequeno porte investe em: gestão da satisfação/reclamação de clientes (86\%), visual merchandising - vitrine, visual de loja e exposição de produtos (83\%) e na gestão do relacionamento/lealdade com clientes $(76 \%)$. Já a grande maioria dos varejistas de médio/grande porte investe em: portfólio de produtos/marcas competitivo (94\%), política de preços competitiva (82\%), gestão da satisfação/reclamação de clientes (76\%), visual merchandising (76\%), monitoramento da internet/redes sociais $(76 \%)$ e conhecimento de mercado/concorrência (76\%). Os varejistas de micro/pequeno porte (62\%) investem mais em integração de canais do que os varejistas de médio/grande porte (41\%). E os varejistas de médio/grande porte (65\%) investem mais em aliança/parcerias com outras empresas do que os varejistas de micro/pequeno porte (30\%). 
Em termos de média aritmética, os resultados de práticas de gestão de marketing multicanal apresentam resultados semelhantes aos apontados na análise de frequência (\%), tendo médias mais elevadas aquelas práticas com maior frequência de utilização. Entretanto, seis variáveis mensuradas apresentam desvio-padrão elevado (superior a $20 \%$ da escala): alianças/parcerias com outras empresas do mercado $(\sigma=1,46)$; integração de canais $(1,34)$; incentiva os clientes no uso de diferentes canais $(1,33)$; ações de comunicação de marketing $(1,22)$; promoção de vendas $(1,20)$; oferta de serviços/pós-venda aos clientes $(1,20)$. As demais variáveis apresentam baixa dispersão das respostas, indicando maior consistência dos dados coletados.

O teste $t$ Student foi utilizado para verificar se há diferença estatística significativa nas práticas de marketing multicanal dos varejistas pesquisados em função do porte (micro/pequena versus médio/grande), ao nível de significância ( $P$-value) de 0,05. As hipóteses estabelecidas são: $\mathrm{H}_{1}=$ há diferença estatística significativa nas práticas de marketing multicanal em função do porte; $\mathrm{H}_{0}=$ não há diferença estatística significativa nas práticas de marketing multicanal em função do porte. Os resultados sugerem a rejeição da hipótese $\mathrm{H}_{0}$ apenas para as variáveis: investe em promoção de vendas $(t=-3,809 ; p=0,000)$ e investe em alianças/parcerias com outras empresas/varejistas do mercado $(t=-2,131 ; p=0,036)$. Para as demais variáveis, os resultados indicam que não há diferença estatística significativa nas práticas de marketing multicanal em função do porte do varejista.

Considerando que há diferença significativa em relação ao investimento em promoção de vendas e em alianças/parceiras com outras empresas do varejo em função do porte, acredita-se que os varejistas, principalmente de micro/pequeno porte, precisam investir mais nestas práticas de marketing multicanal, pois podem contribuir para aumentar o volume de vendas, obter diferencial competitivo e melhorar a satisfação dos clientes (JIN; PARK; KIM, 2010), e consequentemente melhorar o desempenho dos canais de vendas (BERNSTEIN; SONG; ZHENG, 2008).

\subsection{Resultados de práticas de integração de canais}

O Gráfico 2 apresenta os resultados de práticas de integração dos canais (somatório percentual das escalas 4 e 5) - por porte/tamanho e total, incluindo média e desvio-padrão. Os 
resultados indicam que a maioria dos varejistas pesquisados investe em todas as práticas de integração de canais mensuradas, porém apenas a grande maioria deles (mais de 2/3) investe em: integração na logística (90\%); integração no suprimento/compra de produtos $(87 \%)$; integração na política de preços (82\%); integração na política de vendas (81\%); integração no ambiente/layout dos canais (80\%); integração na comunicação de marketing (80\%).

Os resultados indicam, também, que os varejistas de pequeno/médio porte investem mais em integração de canais que os varejistas de médio/grande porte. Somente na prática de integração da comunicação de marketing os varejistas de médio/grande porte (88\%) investem mais do que os varejistas de micro/pequeno (77\%). Esses resultados divergem dos achados de Bruce et al. (2009), segundo o qual a integração de canais é mais comum nas empresas maiores. Talvez na região Grande Florianópolis/SC essa prática seja favorecida pelas características das empresas de pequeno porte, predominantes no estudo. Segundo Pacagnan e Rampazo (2008), tais características são: estrutura organizacional enxuta, processos organizacionais simplificados e coordenação de processo centralizada.

Cabe destacar, ainda, que há seis variáveis que apresentam desvio-padrão elevado: integração na divisão de resultados/lucros $(\sigma=1,58)$; integração na troca/devolução de produtos $(\sigma=1,37)$; integração no sistema de dados/informações $(\sigma=1,31)$; integração na estrutura de pessoal $(\sigma=1,30)$; gestão dos conflitos/divergências entre canais $(\sigma=1,20)$; integração na política de vendas $(\sigma=1,20)$. As demais variáveis apresentam desvio-padrão em níveis aceitáveis, indicando baixa dispersão dos dados coletados.

O teste $t$-Student foi utilizado para verificar diferenças estatísticas significativas nas práticas de integração de canais dos varejistas pesquisados em função do porte (micro/pequena versus médio/grande), ao nível de significância $(P$-value) de 0,05 . Os resultados sugerem que há diferença estatística significativa apenas para as variáveis: integração na política de produtos $(t=3,064 ; p=0,003)$ e integração na política de preços $(t=2,526 ; p=0,014)$. Para as demais variáveis, os resultados apontam que não há diferença estatística significativa nas práticas de integração de canais dos varejistas em função do porte. 
Gráfico 2 - Resultados de integração dos canais (escalas 4 e 5), por porte e total

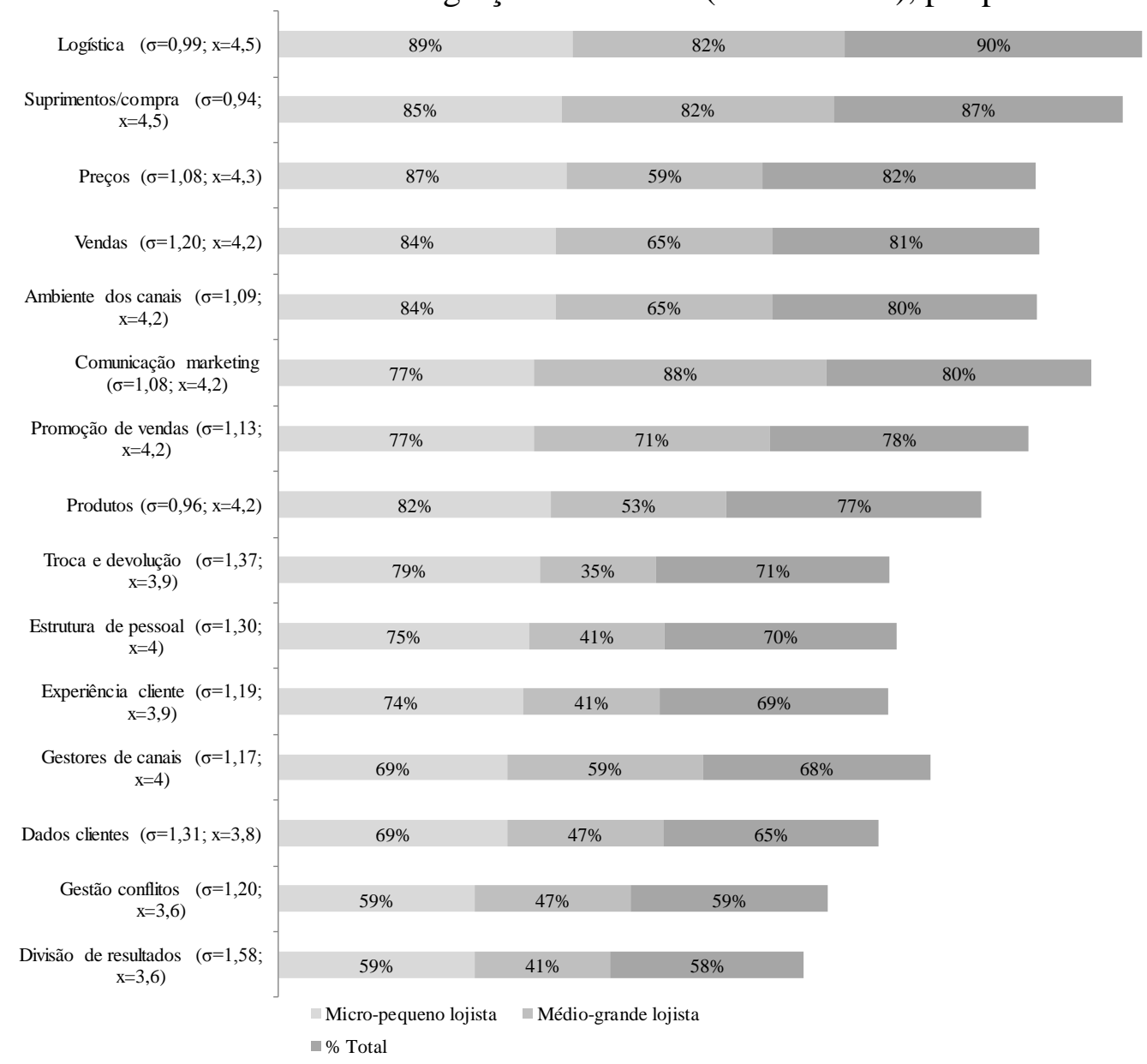

Fonte: elaboração própria.

Embora o estudo tenha revelado que só há diferença estatística significativa entre o porte para a prática de integração de canais na política de produtos e de preços, sabe-se que diversos autores defendem a importância da integração de canais no varejo, em função dos benefícios proporcionados (BRUCE et al., 2009; CAO; LI, 2015; MELIS et al., 2015; VANHEEMS; KELLY; STEVENSON, 2013; XIA; ZHANG, 2010). Jones e Livingstone (2015) identificam que o uso simultâneo de canais off-line e on-line contribui para a complementaridade e desempenho dos canais. Contudo, o resultado do presente estudo pode estar alinhado com outros que questionaram a necessidade da estratégia de integrar canais justamente porque há muitos casos de varejistas multicanais operando com sucesso com canais não plenamente integrados (ANDREINI; PEDELIENTO, 2014; VAN BAAL, 2014; MÜLLER-LANKENAU; WEHMEYER; KLEIN, 2006). Além disso, Van Baal (2014), por exemplo, apontou que integrar canais pode oferecer desvantagens, como a canibalização de canais, redução de vendas e complexidade de gestão. Portanto, o varejista precisa analisar, de 
forma ampla e considerando as características do negócio e do mercado, as possibilidades, vantagens e desvantagens da integração de canais para o seu negócio.

Com relação aos resultados deste estudo - não apresentar diferença significativa em função do porte das empresas na maioria das variáveis analisadas, tanto nas práticas de gestão de marketing como de integração de canais -, pode-se supor a existência de outros fatores que contribuem para o desempenho competitivo. Embora as grandes empresas tendam a ter facilidade de acesso a recursos e mercados e gerar economia de escala (GHEMAWAT, 1998; MATTAR, 2011), possibilitando trabalhar com essas práticas de marketing, esse resultado de diferença não significativa corrobora com os achados de Ribeiro, Rosseto e Verdinelli (2011), que identificou que a simples disponibilidade de recursos não é suficiente para assegurar melhor desempenho competitivo.

No entanto, o estudo de Pentina, Pelton e Hasty (2009), identificou que tamanho da empresa pode ajudar a superar eventuais desafios e resultados negativos quando da entrada no mercado multicanal, justamente pelas empresas grandes terem mais capital, infraestrutura e recursos humanos para investir em práticas de marketing multicanal. Este capital, infraestrutura e recursos que as empresas maiores possuem pode ter influenciado na prática de maior investimento em promoção de vendas e em alianças/parcerias com outras empresas/varejistas do mercado, diferente dos varejistas de micro/pequeno porte.

\subsection{Resultados de desempenho competitivo dos varejistas}

A Tabela 1 mostra os resultados de desempenho competitivo dos varejistas pesquisados em relação à concorrência, na avaliação dos gestores pesquisados (frequência relativa) - por porte e total. O desempenho foi mensurado segundo os critérios: volume de vendas, lucratividade das vendas, participação de mercado, satisfação dos clientes, lealdade dos clientes e o desempenho geral. 
Tabela 1 - Resultados de desempenho em relação à concorrência, por porte e total

\begin{tabular}{|l|c|c|c|c|c|c|c|c|c|}
\hline \multicolumn{1}{c}{ Critérios } & $\begin{array}{c}\text { Micro e } \\
\text { pequena }\end{array}$ & $\begin{array}{c}\text { Média e } \\
\text { grande }\end{array}$ & Total & $\begin{array}{c}\text { Micro e } \\
\text { pequena }\end{array}$ & $\begin{array}{c}\text { Média e } \\
\text { grande }\end{array}$ & Total & $\begin{array}{c}\text { Micro e } \\
\text { pequena }\end{array}$ & $\begin{array}{c}\text { Média e } \\
\text { grande }\end{array}$ & Total \\
\hline $\begin{array}{l}\text { Volume de } \\
\text { vendas (n=72) }\end{array}$ & $18 \%$ & $13 \%$ & $17 \%$ & $16 \%$ & $27 \%$ & $18 \%$ & $67 \%$ & $60 \%$ & $65 \%$ \\
$\begin{array}{l}\text { Lucratividade } \\
\text { (n=71) }\end{array}$ & $14 \%$ & $0 \%$ & $11 \%$ & $20 \%$ & $40 \%$ & $24 \%$ & $66 \%$ & $60 \%$ & $65 \%$ \\
$\begin{array}{l}\text { Participação } \\
\text { mercado (n=76) }\end{array}$ & $13 \%$ & $25 \%$ & $16 \%$ & $10 \%$ & $25 \%$ & $13 \%$ & $77 \%$ & $50 \%$ & $71 \%$ \\
$\begin{array}{l}\text { Satisfação } \\
\text { clientes (n=79) }\end{array}$ & $2 \%$ & $6 \%$ & $3 \%$ & $6 \%$ & $13 \%$ & $8 \%$ & $92 \%$ & $81 \%$ & $90 \%$ \\
$\begin{array}{l}\text { Lealdade } \\
\text { clientes (n=79) }\end{array}$ & $3 \%$ & $6 \%$ & $4 \%$ & $11 \%$ & $13 \%$ & $11 \%$ & $86 \%$ & $81 \%$ & $85 \%$ \\
$\begin{array}{l}\text { Desempenho } \\
\text { geral (n=77) }\end{array}$ & $7 \%$ & $6 \%$ & $6 \%$ & $16 \%$ & $25 \%$ & $18 \%$ & $77 \%$ & $69 \%$ & $75 \%$ \\
\hline
\end{tabular}

Fonte: elaboração própria.

A maioria dos varejistas pesquisados (mais de 50\%) declarou ter desempenho competitivo melhor que a concorrência em todos os critérios de desempenho analisados, principalmente em satisfação de clientes (90\%), lealdade de clientes (85\%), desempenho competitivo geral $(75 \%)$ e participação de mercado $(71 \%)$. No entanto, um percentual significativo de varejistas declarou ter desempenho competitivo pior que a concorrência nos critérios: volume de vendas (17\%), participação de mercado (16\%) e lucratividade de vendas $(11 \%)$. E parte significativa deles declarou, também, ter desempenho competitivo igual à concorrência nos critérios lucratividade de vendas (24\%), volume de vendas (18\%) e desempenho geral (18\%).

Os resultados mostram que há maior percentual de varejistas de micro/pequeno porte com desempenho melhor que a concorrência. Uma possível explicação pode ser o fato de as empresas de pequeno porte terem maior proximidade com os clientes, favorecendo a familiaridade com os clientes, atendimento personalizado e a flexibilidade no atendimento de necessidades específicas, como apontado por Cavazza et al. (2014). Cabe ainda destacar que $25 \%$ dos varejistas de médio/grande porte declararam ter desempenho pior que a concorrência em participação de mercado, e que nenhum deles declarou ter desempenho pior que a concorrência em lucratividade de vendas. Um percentual expressivo de varejistas de micro/pequeno porte declarou ter desempenho pior que a concorrência em volume de vendas (18\%), lucratividade de vendas (14\%) e participação de mercado (13\%). Isso pode indicar que, na região estudada, um critério de desempenho valorizado pelos varejistas de 
médio/grande porte é a lucratividade de vendas, como apontado por Venkatesan, Kumar e Ravishanker (2007).

No geral, como apontado por Xia e Zhang (2010), os resultados indicam que a estratégia de marketing multicanal pode estar contribuindo para o desempenho competitivo dos varejistas pesquisados, principalmente em satisfação de clientes, lealdade de clientes, desempenho geral e participação de mercado. Esses varejistas poderiam obter melhor desempenho em volume de vendas, lucratividade e participação de mercado se investissem mais nas práticas de serviços aos clientes, qualificação de funcionários, comunicação de marketing e em sistema de avaliação do desempenho de canais, como sugerem Kotler e Keller (2012).

O teste Anova one-way foi realizado para examinar possível diferença estatística no desempenho competitivo dos varejistas em função do porte (micro/pequena versus médio/grande), ao nível de significância (Sig) de 0,05. Os resultados de valor estatístico de nenhuma das variáveis analisadas atenderam ao nível de significância desejado: desempenho geral $(\mathrm{F}=2,962 ; \mathrm{Sig}=0,058)$, desempenho em vendas $(\mathrm{F}=0,817 ; \mathrm{Sig}=0,446)$, desempenho em lucratividade $(\mathrm{F}=0,605 ; \mathrm{Sig}=0,549)$, desempenho em participação de mercado $(\mathrm{F}=2,587$; Sig=0,082), desempenho em satisfação de clientes (F=0,809; Sig=0,449) e desempenho em lealdade de clientes $(\mathrm{F}=0,915 ; \mathrm{Sig}=0,405)$. Assim, os resultados indicam que não há diferença estatística significativa no desempenho competitivo dos varejistas pesquisadas em função do porte.

\subsection{Resultados da análise de cluster dos varejistas}

Um dos objetivos específicos do presente estudo é classificar os varejistas pesquisados em clusters com base nas práticas de gestão de marketing multicanal. Para tanto, a técnica estatística Cluster Analysis foi empregada para obter o agrupamento das organizações pesquisadas com base nas variáveis/práticas mensuradas (AAKER; KUMAR; DAY, 2009). Conforme Hair et al. (2010), essa técnica é apropriada para estudos com menor quantidade de observações/casos. Na aplicação da Cluster Analysis, utilizou-se o procedimento de aglomeração hierárquica - aquele que estabelece uma hierarquia na formação dos agrupamentos dos casos (AAKER; KUMAR; DAY, 2009). No processamento dos casos, o método de Ward foi utilizado, pois permite utilizar a similaridade para juntar os casos, 
maximizando a homogeneidade dentro dos grupos/clusters. A medida de distância utilizada foi a distância quadrática euclidiana (ou absoluta), a forma mais comumente utilizada para medir similaridade (MALHOTRA, 2012). Com auxílio da técnica Dendrograma, decidiu-se por agrupar os casos em quatro clusters e identificá-los a partir da tabela de associação de clusters e dos respectivos centroides: o cluster 1 ficou com 23 casos (34\% da amostra), o cluster 2 com 20 casos (29\%), o cluster 3 ficou com 12 casos (18\%) e o cluster 4 com 13 $\operatorname{casos}(19 \%)$.

O Quadro 1 apresenta a descrição resumida do nome, tamanho e perfil de cada cluster identificado, incluindo suas características em termos de práticas de gestão de marketing multicanal e desempenho competitivo. Os resultados do teste F da ANOVA one-way indicam que há diferença estatística significativa entre os clusters identificados, evidenciando a existência de heterogeneidade nas práticas de gestão de marketing multicanal dos varejistas analisados.

Quadro 1 - Perfis dos clusters identificados

\begin{tabular}{|c|c|c|}
\hline Cluster & Perfil & Anova \\
\hline $\begin{array}{l}\text { "PIONEIROS" } \\
23 \text { lojistas }(34 \%)\end{array}$ & $\begin{array}{l}\text { Varejistas com mais experiência em multicanal, predominantemente dos } \\
\text { ramos de artigos de vestuário, calçados e acessórios e de casa, móveis e } \\
\text { decorações; oferecem os canais loja de rua, redes sociais, loja virtual e } \\
\text { venda por e-mail; investem principalmente em mix de produtos } \\
\text { competitivos, visual merchandising, política de preços competitivos, } \\
\text { promoções de vendas, conhecimento de mercado/concorrência, alianças } \\
\text { estratégicas com outras empresas e integração de canais; busca a integração } \\
\text { de canais via política de preços, logística, política de vendas, comunicação } \\
\text { de marketing, promoção de vendas, ambiente/layout e sistema de } \\
\text { dados/informações. Varejistas com bom desempenho competitivo nos } \\
\text { diferentes critérios mensurados. }\end{array}$ & $\begin{array}{l}\mathrm{F}= \\
3,290 \\
\mathrm{Sig}= \\
0,000\end{array}$ \\
\hline $\begin{array}{l}\text { "EXPERIENTES" } \\
20 \text { lojistas }(29 \%)\end{array}$ & $\begin{array}{l}\text { Varejistas com boa experiência em multicanal, predominantemente do ramo } \\
\text { de casa, móveis e decorações; oferecem os canais: redes sociais, vendas por } \\
\text { e-mails, loja de rua, loja virtual e telemarketing; investem principalmente } \\
\text { nas práticas de relacionamento/lealdade com clientes; satisfação/reclamação } \\
\text { de clientes; conhecimento de mercado/concorrência e serviços aos clientes; } \\
\text { busca a integração de canais via política de compras, logística e mix de } \\
\text { produtos. Varejistas com bom desempenho competitivo em satisfação e } \\
\text { lealdade de clientes. }\end{array}$ & $\begin{array}{l}\mathrm{F}= \\
2,962 \\
\mathrm{Sig}= \\
0,000\end{array}$ \\
\hline $\begin{array}{l}\text { "MENOS } \\
\text { EXPERIENTES" } \\
12 \text { lojistas (18\%) }\end{array}$ & $\begin{array}{l}\text { Varejistas com pouca experiência em multicanal, principalmente dos ramos } \\
\text { de artigos de vestuário, calçados e acessórios, e de brinquedos e games; } \\
\text { oferecem os canais: redes sociais, loja de rua, loja virtual e loja de } \\
\text { shopping; investem principalmente em visual merchandising, integração de } \\
\text { canais, incentivo ao uso de diferentes canais, monitoramento da internet, } \\
\text { avaliação do desempenho dos canais, comunicação de marketing; buscam a } \\
\text { integração de canais via mix de produtos, política de troca/devolução, } \\
\text { compras, política de preços, comunicação de marketing, promoção de } \\
\text { vendas, ambiente/layout, estrutura de pessoal. Varejistas com melhor } \\
\text { desempenho competitivo em todos os critérios analisados. }\end{array}$ & \begin{tabular}{|l|}
$\mathrm{F}=$ \\
2,844 \\
$\mathrm{Sig}=$ \\
0,000
\end{tabular} \\
\hline
\end{tabular}


(CONTINUAÇÃO)

\begin{tabular}{|c|c|c|}
\hline $\begin{array}{l}\text { "RETARDATÁRIOS" } \\
13 \text { lojistas (19\%) }\end{array}$ & $\begin{array}{l}\text { Varejistas com menos experiência multicanal, predominantemente dos } \\
\text { ramos de artigos de vestuário, calçados e acessórios e artigos para esporte e } \\
\text { lazer; oferecem os canais loja de rua, redes sociais, loja virtual e } \\
\text { telemarketing; investem principalmente em política de preços competitiva e } \\
\text { em promoção de vendas; com pouca integração de canais. Varejistas com } \\
\text { bom desempenho competitivo geral, mas com as piores médias em } \\
\text { satisfação e lealdade de clientes. }\end{array}$ & $\begin{array}{l}F= \\
2,576 \\
\mathrm{Sig}= \\
0,000\end{array}$ \\
\hline
\end{tabular}

Fonte: elaboração própria.

O cluster 1, denominado "pioneiros", contém os varejistas com mais experiência em multicanal (média 7,5 anos), com maior quantidade de funcionários (média 909), maior quantidade de lojas (média 6,9) e os que mais investem em marketing (média 5,1\% do faturamento anual). Nele, predominam os varejistas dos ramos de artigos de vestuário, calçados e acessórios $(34,8 \%)$ e de casa, móveis e decorações $(26,1 \%)$; aqueles que oferecem os canais loja de rua (87\%), redes sociais (78\%), loja virtual (57\%) e venda por e-mail (48\%). As práticas de gestão de marketing multicanal mais utilizadas são: portfólio de produtos/marcas competitivo (4,6), visual merchandising $(4,6)$, política de preços competitivos $(4,6)$, promoções de vendas $(4,4)$, conhecimento de mercado e concorrência $(4,2)$, alianças estratégicas com outras empresas $(4,00)$ e sistemas de dados/informações sobre clientes $(3,8)$. Os varejistas investem pouco em práticas de integração de canais, basicamente integração na política de produtos $(4,0)$, logística $(4,2)$, política de vendas $(4,0)$, e estrutura de pessoal $(3,8)$. Os varejistas deste cluster têm bom desempenho competitivo nos critérios mensurados, principalmente no desempenho geral $(4,1)$, na lealdade dos clientes $(4,2)$ e na satisfação dos clientes $(4,3)$.

O cluster 2, denominados "experientes", contém os varejistas com boa experiência em multicanal (média 7,3 anos), quantidade elevada de funcionários (média 103), reduzida quantidade de lojas (média 3) e com investimento moderado em marketing (média 2,8\% do faturamento). Nele, predominam os varejistas do ramo de casa, móveis e decorações (35\%), e aqueles que oferecem os canais redes sociais (80\%), vendas por e-mails (65\%), loja de rua (60\%), loja virtual $(60 \%)$ e telemarketing $(45 \%)$. As práticas de gestão de marketing mais utilizadas são: gestão do relacionamento/lealdade de clientes $(4,6)$, gestão da satisfação/reclamação de clientes $(4,6)$, serviços aos clientes $(4,1)$ e qualificação/incentivo de funcionários $(3,8)$. Para integração de canais, esses varejistas investem principalmente na integração da logística $(4,82)$ e dos gestores dos canais $(4,1)$. Os varejistas deste cluster têm bom desempenho competitivo em satisfação de clientes $(4,7)$ e lealdade de clientes $(4,5)$, mas têm desempenho geral $(3,5)$ menor que a média dos demais clusters. 
O cluster 3, nomeado "menos experientes", contém os varejistas com pouco tempo de multicanal (média 3,8 anos), reduzida quantidade de funcionários (média 9) e lojas (média 1,8), e com investimento moderado em marketing (média 2,4\%). Nele, predominam os varejistas dos ramos de artigos de vestuário, calçados e acessórios (50\%), e de brinquedos e games $(16,7 \%)$; aqueles que oferecem os canais redes sociais $(100 \%)$, loja de rua $(75 \%)$, loja virtual (75\%) e loja de shopping (41,7\%). As práticas de gestão de marketing multicanal mais utilizadas são: visual merchandising (5), integração de canais (4,9), incentiva o uso de diferentes canais pelos clientes $(4,6)$, monitora internet/redes sociais $(4,6)$, avalia o desempenho dos diferentes canais $(4,5)$ e comunicação de marketing $(4,0)$. Este cluster contém os varejistas que mais investem em práticas de integração de canais e com as melhores médias de desempenho nos critérios analisados, principalmente no desempenho geral $(4,9)$ e na participação de mercado $(4,9)$.

Por fim, o cluster 4, denominado "retardatários", contém os varejistas mais recentes no uso da estratégia de marketing multicanal (média 2,6 anos), com quantidade elevada de funcionários (média 216), quantidade reduzida de lojas (média 3) e baixo investimento em marketing (média 1,3\%). Nele, predominam os varejistas dos ramos de artigos de vestuário, de calçados e acessórios (54\%) e de artigos para esporte e lazer (23\%); aqueles que oferecem os canais loja de rua (85\%), redes sociais (85\%), loja virtual (31\%) e telemarketing (23\%). As práticas de gestão de marketing multicanal mais utilizadas são: política de preços competitiva $(4,3)$ e promoção de vendas $(4,2)$. Esses varejistas investem pouco na integração de canais, basicamente integração na política de vendas $(4,4)$, política de preços $(4,4)$, logística $(4,6)$ e gestores de canais $(4,1)$. Este cluster contém os varejistas com bom desempenho geral $(4,3)$, satisfação de clientes $(4,1)$ e lealdade de clientes $(4,1)$.

Os resultados da análise de cluster demonstram que, curiosamente, os varejistas menores e com pouco tempo de multicanal (cluster 3) revelaram ter melhor desempenho geral que aqueles com mais tempo de experiência. Contudo, percebe-se que esse grupo trabalha bem com integração de canais, uma prática com impacto positivo sobre o desempenho competitivo dos varejistas (GALLINO; MORENO, 2014). Além disso, esse grupo incentiva o uso de diferentes canais pelos clientes, monitora as redes sociais e avalia com frequência o desempenho dos seus diferentes canais. Esses aspectos podem ter contribuído para melhorar a confiança do cliente, para facilitar o processo de pesquisa por produtos/preços e para reduzir a procura por ofertas dos concorrentes, conforme revelado no estudo de Chatterjee (2006). Isso favorece o desempenho competitivo. Uma outra possível explicação para a boa integração de 
canais do cluster 3 é que os varejistas de micro/pequeno porte são menos departamentalizados e um mesmo gestor pode ser o responsável por todos os canais de vendas da empresa, gerando menos conflitos internos e um processo de gestão mais alinhado e integrado (GALLINO; MORENO; 2014), reduzindo a confusão no cenário de compra (BROLIO; ESPARTEL, 2016). No entanto, conforme Vanheems, Kelly e Stevenson (2013), a integração de canais requer cuidado na oferta da mesma qualidade de serviços nos diferentes canais de vendas/atendimento.

\section{CONCLUSÕES}

O presente estudo analisou as práticas de gestão de marketing multicanal de varejistas de bens de consumo da Grande Florianópolis. Os resultados revelaram que muitos varejistas utilizam, além da loja física, canais eletrônicos, incluindo redes sociais, loja virtual e e-mails. A maioria deles investe em gestão de marketing multicanal, sendo as práticas mais utilizadas a gestão da satisfação/reclamação de clientes, o visual merchandising, o portfólio de produtos/marcas competitivos, a gestão do relacionamento/lealdade com clientes e o monitoramento da Internet/redes sociais. Para obter integração de canais, a maioria dos varejistas investe em integração na logística, no suprimento/compra de produtos, na política de preços, na política de vendas, no ambiente/layout dos canais e na comunicação de marketing.

Os resultados apontaram que os varejistas de micro/pequeno porte investem mais do que os de médio/grande porte em integração de canais. Os varejistas de médio/grande porte investem mais em alianças/parcerias com outras empresas do que os de micro/pequeno porte. As análises do teste $\underline{t \text { Student }}$ apontaram diferenças estatísticas significativas nas práticas de promoção de vendas e de alianças/parcerias com outras empresas em função do porte/tamanho do varejista, e com relação às práticas de integração de canais na política de produtos e na política de preços. Nas demais práticas de gestão de marketing multicanal mensuradas, os resultados dos testes estatísticos apontam não haver diferença significativa em função do porte do varejista.

Com relação ao desempenho competitivo, a maioria dos varejistas pesquisados se avalia como melhor do que a concorrência. O percentual de varejistas de micro/pequeno porte com desempenho melhor que a concorrência é maior do que nos varejistas de médio/grande 
porte. No entanto, o resultado do teste Anova one-way indicou não haver diferença estatística significativa no desempenho competitivo dos varejistas em função do porte.

Os resultados do estudo revelaram, ainda, a existência de quatro clusters de varejistas multicanal na região da Grande Florianópolis e que há diferença estatística significativa entre os clusters identificados com relação às práticas de gestão de marketing multicanal. O cluster 1, denominado "pioneiros", que contém aqueles varejistas com mais experiência em multicanal; o cluster 2, denominado "experientes", contendo os varejistas com boa experiência em multicanal; o cluster 3, nomeado "menos experientes", que contém os lojistas com pouco tempo de experiência em multicanal; o cluster 4, denominado "retardatários", composto pelos lojistas que investiram mais recentemente em práticas de multicanal.

Como contribuição teórica, o estudo possibilitou ampliar o conhecimento sobre as práticas de gestão de marketing multicanal de varejistas de bens de consumo, com base nos dados coletados na região Grande Florianópolis/SC, Brasil. Os resultados contêm, também, evidências empíricas sobre o desempenho competitivo dos varejistas multicanais pesquisados e possibilitaram a identificação de clusters de varejistas multicanal do setor de bens de consumo na região pesquisada. Possibilitaram, ainda, o exame de diferenças estatísticas nas práticas de gestão de marketing multicanal e no desempenho competitivo dos varejistas em função do porte/tamanho. Além disso, diferentemente da maioria dos estudos anteriores sobre o tema, geralmente realizados segundo a perspectiva dos consumidores, o presente estudo empreendeu uma investigação na perspectiva dos gestores varejistas (proprietários, gerentes de lojas ou gestores de marketing), o que contribui para o avanço na compreensão do fenômeno investigado.

Cabe ainda destacar que o estudo possibilitou o desenvolvimento e teste de uma escala de mensuração da prática de gestão de marketing multicanal e da prática de integração de canais de varejistas de bens de consumo, algo que contribui para a realização de futuros estudos sobre o tema. Embora tenha sido baseado na literatura, o questionário aplicado contém escalas de mensuração desenvolvidas e testadas especificamente para o propósito do presente estudo. Além disso, as variáveis das escalas apresentadas possibilitam melhorar a compreensão sobre elementos que compõem os constructos gestão de marketing multicanal e integração de canais, no contexto do varejo. E mostram que a integração de canais é um constructo complexo e multifacetado, que envolve não somente a integração de pessoal, mas esforços de interação no âmbito das diferentes práticas de marketing dos canais de vendas/distribuição. 
Algumas recomendações gerenciais podem ser apresentadas com base nos resultados do presente estudo. Recomenda-se aos varejistas pesquisados (principalmente os lojistas de médio e grande portes) investirem mais no uso simultâneo de diferentes canais e na utilização de outros canais eletrônicos, como loja virtual e outros varejistas on-line, e em aplicativos em tablet/smartphone, pois no Brasil o consumidor utiliza mais estes aparelhos para acessar a internet (REVISTA EXAME, 2016). Para os varejistas de micro/pequeno porte, sugere-se também investir mais em alianças/parcerias com outras empresas/varejistas, como organizações especializadas em serviços de logística, tecnologia e comunicação de marketing. Pode também fazer parcerias com empresas de marketplace (ex: Submarino ou Magazine Luiza), pois isto pode reduzir a necessidade de investimentos na manutenção de loja virtual e gerar maior visibilidade de mercado e volume de negócios.

Acredita-se, também, que os varejistas de micro/pequeno porte poderiam obter melhor desempenho em volume de vendas, lucratividade e participação de mercado se investisse mais em serviços aos clientes, qualificação de funcionários, comunicação de marketing e em sistema de avaliação do desempenho de canais. E, como a integração de canais tem impacto no desempenho competitivo, recomenda-se aos varejistas dos clusters 1 (pioneiros) e 4 (retardatários) investirem mais na integração de canais, principalmente na gestão de conflitos e nas práticas de integração de gestores, estrutura de pessoal e dados/informações sobre clientes. Além disso, como são mais departamentalizados (divididas), as grandes empresas tendem a ter mais falhas de integração de canais e carecer mais de alinhamento de objetivos, metas e prioridades, e de ações de marketing interno. No âmbito dos dados/informações, esses varejistas precisam também operar com o mesmo sistema informatizado (ERP) nas diferentes lojas e unidade, e promover junto aos funcionários a prática de alimentação de dados/informações sobre clientes, estoques e mercados. Há ainda necessidade de melhorar o conhecimento dos gestores varejistas sobre práticas de marketing multicanal, o que pode ser feito pela participação em eventos e seminários promovidos pelas entidades de classe do setor (ex: Fecomércio e CDL).

Como limitações do estudo, destaca-se o método de amostragem empregado (não probabilístico), que torna os resultados não possível de generalização para o setor/região estudado. O critério de classificação dos varejistas por porte (quantidade de funcionário, segundo SEBRAE, 2017) pode ter contribuído para gerar alguma imprecisão na verificação de diferenças estatísticas entre varejistas de micro/pequeno e médio/grande porte. Além disso, como a quantidade de varejistas de médio/grande porte participantes foi relativamente 
pequena, as análises estatísticas por porte podem ter sido afetadas. A atual situação da economia brasileira (crise econômica a partir de 2014) pode ter, também, influenciado negativamente a opinião dos gestores sobre o desempenho competitivo dos varejistas. Assim, propõe-se que novos estudos sobre o tema sejam realizados. Há necessidade de novas pesquisas quantitativas com amostra mais representativa, seja maior quantidade de participantes ou processo de amostragem probabilístico; de estudos em outras mesorregiões do Estado de Santa Catarina ou em outros estados do Brasil, comparando os resultados com os achados no presente estudo. Há, também, carência de estudos com varejistas dos setores de serviços ou bens industriais. E de estudos qualitativos que possam auxiliar na compreensão mais aprofundada das práticas de integração de canais dos varejistas de bens de consumo, incluindo nível de integração, amplitude da integração, estratégias de integração e barreiras para integração.

\section{REFERÊNCIAS}

ANDREINI, D.; PEDELIENTO, G. Is multichannel integration in retailing a source of competitive advantage? In: MUSSO, F.; DRUICA, E. (Org.). Handbook of Research on Retailer: consumer relationship development. IGI Global, 2014. p. 471-489.

ANSARI, A.; MELA, C.; NESLIN, S. Customer channel migration. Journal of Marketing Research, v. 45, n. 1, p. 60-76, 2008.

AUBREY, C.; JUDGE, D. Re-imagine retail: why store innovation is key to a brand's growth in the 'new normal', digitally-connected and transparent world. Journal of Brand Strategy, v. 1 n. 1, p. 31-39, 2012.

BERNSTEIN, F.; SONG, J.; ZHENG, X".Bricks-and-mortar" vs “clicks-and-mortar": an equilibrium analysis. European Journal of Operational Research, v. 187, n. 3, p. 671-690, 2008.

BERRY, L.; BOLTON, R.; BRIDGES, C.; MEYER, J.; PARASURAMAN, A.; SEIDERS, $\mathrm{K}$. Opportunities for innovation in the delivery of interactive retail services. Journal of Interactive Marketing, v. 24, n. 2, p. 155-167, 2010.

BROLIO, P.; ESPARTEL, L. Confusão do consumidor no cenário multimídia e multicanal: definição do construto e agenda de pesquisa. Revista Brasileira de Marketing, v. 15, n 1, 2016. 
BRUCE, L.; BONDY, K.; STREET, R.; WILSON, H. Channel evolution: how new multichannel thinking can deliver competitive advantage. Journal of Direct, Data and Digital Marketing Practice, v. 10, n. 4, p. 329-335, 2009.

BRYNJOLFSSON, E.; HU, Y.; RAHMAN, M. Competing in the age of omnichannel retailing. MIT Sloan Management Review, v. 54, n. 4, p. 23-29, 2013.

CAO, L. Business model transformation in moving to a cross-channel retail strategy: a case study. International Journal of Electronic Commerce, v. 18, n. 4, p. 69-96, 2014.

; LI, L. The impact of cross-channel integration on retailers' sales growth. Journal of Retailing, v. 91, n. 2, p. 198-216, 2015.

CAVAZZA, B.; ALCÂNTARA, V.; SETTE, R.; ANTONIALLI, L. Estratégias de marketing em Micro e pequenas empresas de varejo: estudo de múltiplos casos no sul de Minas Gerais. Revista da Micro e Pequena Empresa, v. 8, n. 3, p. 52-65, 2014.

CHATTERJEE, P. Cross-channel product ordering and payment policies in multichannel retailing: implications for shopping behavior and retailer profitability. Journal of Shopping Center Research, v. 13, n. 2, p. 31-56, 2006.

COUGHLAN, A.; ANDERSON, E.; STERN, L.; EL-ANSARY, A. Canais de marketing. São Paulo: Pearson Education do Brasil, 2012.

CRONBACH, L. Coefficient alpha and the internal structure of tests. Psychometrika, v. 16, n. 3, p. 297-334, 1951.

DAY, G. S.; WENSLEY, R. Assessing Advantage: for Framework Diagnosing Superiority Competitive. Journal of Marketing, v. 52, n. 2, p. 1-20, Apr. 1988.

DEPEC - Departamento de Pesquisas e Estudos Econômicos do Bradesco. Comércio varejista. Disponível em: <http://www.economiaemdia.com.br/EconomiaEmDia/pdf/infset_comercio_varejista.pdf $>$. Acesso em: 05 mar. 2016.

DHOLAKIA, R.; ZHAO, M.; DHOLAKIA, N. Multichannel retailing: a case study of early experiences. Journal of Interactive Marketing, v. 19, n. 2, p. 64-74, 2005. 
DIAS, S. O desafio do varejo multicanal: comportamento free-riding do consumidor. $337 \mathrm{f}$. Tese (Doutorado em Administração) - Faculdade de Economia, Administração e Contabilidade, Universidade de São Paulo, São Paulo, 2014.

FECOMÉRCIO-SC. Caderno do comércio de Santa Catarina 2016. Florianópolis, 2016. Disponível em: <http://www.fecomercio-sc.com.br/publicacoes/caderno-do-comercio-desanta-catarina-2016/>. Acesso em: 2 out. 2018.

GALLINO, S.; MORENO, A. Integration of online and offline channels in retail: the impact of sharing reliable inventory availability information. Management Science, p. 1-36, June 2014.

GHEMAWAT, P. Vantagem sustentável. In: MONTGOMERY, C. A.; PORTER, M. E. (Org.) Estratégia: a busca da vantagem competitiva. Rio de Janeiro: Campos, 1998. p. 29.

GRIFFITHS, G.; HOWARD, A. Balancing clicks and bricks-strategies for multichannel retailers. Journal of Global Business Issues, v. 2, n. 1, p. 69-75, 2008.

HERHAUSEN, D.; BINDER, J.; SCHOEGEL, M.; HERRMANN, A. Integrating bricks with clicks: retailer-level and channel-level outcomes of online-offline channel integration. Journal of Retailing, v. 91, n. 2, p. 309-325, 2015.

JIN, B.; PARK, J.; KIM, J. Joint influence of online store attributes and offline operations on performance of multichannel retailers. Behaviour \& Information Technology, v. 29, n. 1, p. 85-96, 2010.

JOHANSSON, T.; KASK, J. Configurations of business strategy and marketing channels for e-commerce and traditional retail formats: A Qualitative Comparison Analysis (QCA) in sporting goods retailing. Journal of Retailing and Consumer Services. v. 34, p. 326-333, 2017.

JONES, C.; LIVINGSTONE, N. Emerging implications of online retailing for real estate: Twenty-first century clicks and bricks. Journal of Corporate Real Estate, v. 17, n. 3, p. 226239, 2015.

KAUFMAN-SCARBOROUGH, C.; LINDQUIST, J. E-shopping in a multiple channel environment. Journal of Consumer Marketing, v. 19, n. 4, p. 333-350, 2002. 
KERSMARK, M.; STAFLUND, L.. Omni-channel retailing: blurring the lines between online and offline. 2015. 63 f. Dissertação (Mestrado in Business Administration) Jönköping International Business School, Jönköping University, Suécia, 2015.

KIM, J.; LEE, H. Consumer product search and purchase behavior using various retail channels: the role of perceived retail usefulness. International Journal of Consumer Studies, v. 32, n. 6, p. 619-627, 2008.

KOTLER, P.; KELLER, K. Administração de marketing. São Paulo: Pearson Prentice Hall, 2012.

KOZLENKOVA, I.; HULT, G.; LUND, D.; MENA, J.; KEKEC, P. The role of marketing channels in supply chain management. Journal of Retailing, v. 91, n. 4, p. 586-609, 2015.

KUMAR, V.; SUNDER, S.; SHARMA, A. Leveraging distribution to maximize firm performance in emerging markets. Journal of Retailing, v. 91, n. 4, p. 627-643, 2015.

KUSHWAHA, T.; SHANKAR, V. Are multichannel customers really more valuable? The moderating role of product category characteristics. Journal of Marketing, v. 77, n. 4, p. 67$85,2013$.

LAN, J. A diversificação dos canais comerciais como fonte de vantagem competitiva em redes de supermercados no Brasil. 2010. 102 f. Dissertação (Mestrado em Administração) Universidade Presbiteriana Mackenzie, São Paulo, 2010.

MALHOTRA, N. Pesquisa de marketing: uma orientação aplicada. Bookman Editora, 2012.

MATTAR, F. Administração de varejo. Rio de Janeiro: Elsevier, 2011.

MELIS, K.; CAMPO, K.; BREUGELMANS, E.; LAMEY, L. The impact of the multichannel retail mix on online store choice: does online experience matter? Journal of Retailing, v. 91, n. 2, p. 272-288, 2015.

MIOTTO, A.; PARENTE, J. Retail evolution model in emerging markets: apparel store formats in Brazil. International Journal of Retail \& Distribution Management, v. 43, n3, p. 242-260, 2015. 
MÜLLER-LANKENAU, C.; WEHMEYER, K.; KLEIN, S. Strategic channel alignment: an analysis of the configuration of physical and virtual marketing channels. Information Systems and e-Business Management, v. 4, n. 2, p. 187-216, 2006.

NESLIN, S.; SHANKAR, V. Key issues in multichannel customer management: current knowledge and future directions. Journal of Interactive Marketing, v. 23, n. 1, p. 70-81, 2009.

OH, L.; TEO, H.; SAMBAMURTHY, V. The effects of retail channel integration through the use of information technologies on firm performance. Journal of Operations Management, v. 30, n. 5, p. 368-381, 2012.

PACAGNAN, M.; RAMPAZO, A. Competitividade no varejo: desafios da colaboração entre os pequenos empresários. Revista da Micro e Pequena Empresa, v. 2, n. 1, p. 3-18, 2008.

PARENTE, J.; BARKI, E. Varejo no Brasil: gestão e estratégia. São Paulo: Atlas, 2014.

PENTINA, I.; PELTON, L.; HASTY, R. Performance implications of online entry timing by store-based retailers: a longitudinal investigation. Journal of Retailing, v. 85, n. 2, p. 177193, 2009.

QUADER, M.; QUADER, M. The utilization of e-commerce by traditional supermarkets in the UK through strategic alliances with internet based companies. Journal of Services Research, v. 8, n. 1, p. 177-211, 2008.

RAPP, A.; BAKER, T.; BACHRACH, D.; OGILVIE, J.; BEITELSPACHER, L. Perceived customer showrooming behavior and the effect on retail salesperson self-efficacy and performance. Journal of Retailing, v. 91, n. 2, p. 358-369, 2015.

REVISTA EXAME. Estatísticas de uso de celular no Brasil. Disponível em: $<$ https://exame.abril.com.br/negocios/dino/estatisticas-de-uso-de-celular-no-brasildino89091436131/>. Acesso em: 5 mai. 2016.

RIBEIRO, R.; ROSSETTO, C.; VERDINELLI, M. Comportamento estratégico da empresa e a visão baseada em recursos: um estudo no setor varejista de material de construção. Gest. Prod., v. 18, n. 1, p. 175-192, 2011.

ROSENBLOOM, B. Multi-channel strategy in business-to-business markets: prospects and problems. Industrial Marketing Management, v. 36, n. 1, p. 4-9, 2007. 
SAUNDERS, M.; LEWIS, P.; THORNHILL, A. Research methods for business students. Pearson Education, 2009.

SEBRAE. Critérios de Classificação de Empresas. Disponível em: <http://www.sebraesc.com.br/leis/default.asp?vcdtexto=4154>. Acesso em: 12 mar. 2017.

VALOS, M. A qualitative study of multi-channel marketing performance measurement issues. Journal of Database Marketing \& Customer Strategy Management, v. 15, n. 4, p. 239-248, 2008.

; POLONSKY, M.; GEURSEN, G.; ZUTSHI, A. Marketers' perceptions of the implementation difficulties of multichannel marketing. Journal of Strategic Marketing, v. 18, n. 5, p. 417-434, 2010.

VAN BAAL, S. Should retailers harmonize marketing variables across their distribution channels?: an investigation of cross-channel effects in multi-channel retailing. Journal of Retailing and Consumer Services, v. 21, n. 6, p. 1038-1046, 2014.

VANHEEMS, R.; KELLY, J. Understanding customer purchase switching behavior when retailers use multiple channels. International Journal of Integrated Marketing Communications, v. 1, n. 2, p. 44-56, 2009.

; KELLY, J.; STEVENSON, K. The Internet, the modern death of a salesman: multichannel retailing's impact on the salesperson's role. International Journal of Integrated Marketing Communications, v. 5, n. 2, p. 91-101, 2013.

VENKATESAN, R.; KUMAR, V.; RAVISHANKER, N. Multichannel shopping: causes and consequences. Journal of Marketing, v. 71, n. 2, p. 114-132, 2007.

VERHOEF, P.; KANNAN, P.; INMAN, J. From multi-channel retailing to omni-channel retailing: introduction to the special issue on multi-channel retailing. Journal of Retailing, $v$. 91, n. 2, p. 174-181, 2015.

WALLACE, D.; JOHNSON, J.; UMESH, U. Multichannels strategy implementation: the role of channel alignment capabilities. Decision Sciences, v. 40, n. 4, p. 869-900, 2009.

WATSON IV, G.; WORM, S.; PALMATIER, R.; GANESAN, S. The evolution of marketing channels: trends and research directions, Journal of Retailing, v. 91 n. 4, p. 546-568, 2015. 
WELTEVREDEN, J. W. J.; BOSCHMA, R. A. Internet strategies and performance of Dutch retailers. Journal of Retailing and Consumer Services, [S. 1.], v. 15, n. 3, p. 163-178, May 2008.

XIA, Y.; ZHANG, G. The impact of the online channel on retailers' performances: an empirical evaluation. Decision Sciences, v. 41, n. 3, p. 517-546, 2010.

YAN, R.; WANG, J.; ZHOU, B. Channel integration and profit sharing in the dynamics of multi-channel firms. Journal of Retailing and Consumer Services, v. 17, n. 5, p. 430-440, 2010 .

ZHANG, J.; FARRIS, P.; IRVIN, J.; KUSHWAHA, T.; STEENBURGH, T.; WEITZ, B. Crafting integrated multichannel retailing strategies. Journal of Interactive Marketing, v. 24, n. 2, p. 168-180, 2010. 
APÊNDICE A

Dimensões e variáveis mensuradas

\begin{tabular}{|c|c|c|}
\hline Dimensão & Variável & Referências \\
\hline $\begin{array}{l}\text { Práticas de } \\
\text { gestão de } \\
\text { marketing } \\
\text { multicanal }\end{array}$ & $\begin{array}{l}\text { Investe em mix de produtos/marcas competitivo } \\
\text { Investe em política de preços competitiva } \\
\text { Investe no relacionamento e lealdade com clientes } \\
\text { Investe na satisfação e na reclamação de clientes } \\
\text { Investe em serviços aos clientes (ex: pós-venda) } \\
\text { Incentiva o cliente a utilizar os diferentes canais } \\
\text { Investe em sistema de informações sobre clientes } \\
\text { Investe em comunicação de marketing (ex: } \\
\text { propaganda) } \\
\text { Investe no monitoramento da internet/redes sociais } \\
\text { Investe em promoção de vendas (desconto, } \\
\text { liquidação) } \\
\text { Investe na qualificação e incentivos de funcionários } \\
\text { Investe em conhecimento de mercado e concorrência } \\
\text { Investe em alianças/parcerias com outras empresas } \\
\text { Investe na integração de canais } \\
\text { Investe em visual merchandising (vitrine, visual de } \\
\text { loja, exposição de produtos) } \\
\text { Avalia o desempenho dos diferentes canais }\end{array}$ & $\begin{array}{l}\text { Neslin e Shankar (2009) } \\
\text { e Zhang et al. (2010). }\end{array}$ \\
\hline $\begin{array}{l}\text { Práticas de } \\
\text { integração de } \\
\text { canais }\end{array}$ & $\begin{array}{l}\text { Há integração na política de produtos } \\
\text { Há integração na troca/devolução de produtos } \\
\text { Há integração no suprimento/compra de produtos } \\
\text { Há integração na política de preços } \\
\text { Há integração na logística (estoques, entrega) } \\
\text { Há integração na política de vendas } \\
\text { Há integração na comunicação de marketing } \\
\text { Há integração na promoçâo de vendas/liquidação } \\
\text { Há integração no ambiente/layout dos canais } \\
\text { Há integração na estrutura de pessoal } \\
\text { Há integração no sistema de dados/informações } \\
\text { Há integração na divisão de resultados/lucros } \\
\text { Há integração na experiência de compra dos clientes } \\
\text { Há gestão dos conflitos/divergências entre canais } \\
\text { Gerente/dirigente único coordena todos os canais }\end{array}$ & $\begin{array}{l}\text { Cao e Li }(2015) \text { e } \\
\text { Kersmark e Staflund } \\
\text { (2015) }\end{array}$ \\
\hline $\begin{array}{l}\text { Avaliação do } \\
\text { desempenho } \\
\text { competitivo }\end{array}$ & $\begin{array}{l}\text { Volume de vendas } \\
\text { Lucratividade de vendas } \\
\text { Participação de mercado } \\
\text { Satisfação dos clientes } \\
\text { Lealdade dos clientes } \\
\text { Desempenho competitivo geral }\end{array}$ & $\begin{array}{l}\text { Day e Wensley (1988) e } \\
\text { Weltevreden e Boschma } \\
(2008)\end{array}$ \\
\hline
\end{tabular}

